\title{
Theoretical Analysis for Local Buckling of Corrugated Steel Plate
}

\author{
Bai Jian LI, Liang Sheng ZHU, Xin Sha FU \\ School of Civil Engineering and Transportation, South China University of Technology, Guangzhou, Guangdong, 510640, China
}

\begin{abstract}
To study local buckling of Corrugated Steel Plate under concentrated loads. Through experimental tests and theorical analysis, bearing capacity and failure form of Corrugated Steel Plate were discussed. Bearing capacity of Corrugated Steel Plate associated with local buckling, which can be assumed to be composed of three parts: buckling of plane rigid frame caused by concentrated loads, buckling of roof and web caused by bending stress. These three parts were unified by buckling relevant equations, then local buckling calculation formula was obtained. Comparing with experimental results, the loads obtained by local buckling calculation formula agree with test results very well. Since the buckling calculation is independent of the material strength, the calculation formula of local buckling is reliable, it can be used to evaluate local buckling of Corrugated Steel Plate.
\end{abstract}

\section{Introduction}

Corrugated Steel Plate (CSP) is pressed or bent corrugated by steel plate, which has high bearing capacity and high stability, has been widely used in bridge and culvert engineering [1-3] and PC box girder with corrugated steel webs [4-11]. In recent years, researchers have developed a new type of structure on the basis of the application of steel-concrete composite deck called corrugated steel-concrete composite bridge deck. This type of structure is first found in a bridge reinforcement project located in Pingnan County, Xunjiang River. The corrugated steel bridge deck was used to improve the shear bearing capacity [12]. Experiments of the corrugated steel-concrete composite bridge deck by Prof. Xu Haiyan and his team obtained load-displacement curves and stress-strain state, which indicated that the structure had characteristics of high bearing capacity and good ductility. Bearing capacity could be calculated by composite structure theory [13]. Prof. Su Qingtian also conducted laboratory experiments, confirming that the corrugated steel-concrete composite bridge deck had the characteristics of light weight, high capacity and high cost; compared with the steel deck, it had the characteristics of low cost, easy to pave, high fatigue strength and high weight; compared with the ordinary steel plate-concrete deck, it had the characteristics of low weight, high shear strength. It is a feasible option in the bridge deck of medium span bridges [14-15].

In summary, the application of corrugated steel plate in multiple fields was studied deeply, but there were more problems need to be solved, such as local stability of the corrugated steel-concrete composite deck, which affects the mechanical properties of composite deck during construction, the present study mainly focus on the shear buckling performance of corrugated steel webs and the buckling of corrugated steel plate arch. There is no research on local buckling of CSP. Therefore, this paper focuses on solving local buckling problem of CSP.

\section{Structural Form and Experimental Test}

\subsection{Structural Form}

Compared with the steel platforms, CSP platform will reduce the number of supporting ribs, greatly increase the span of the structure, and reduce the number of steel reinforced beams. The ends of CSP are usually supported on steel beams or concrete beams with setting connecting bars.

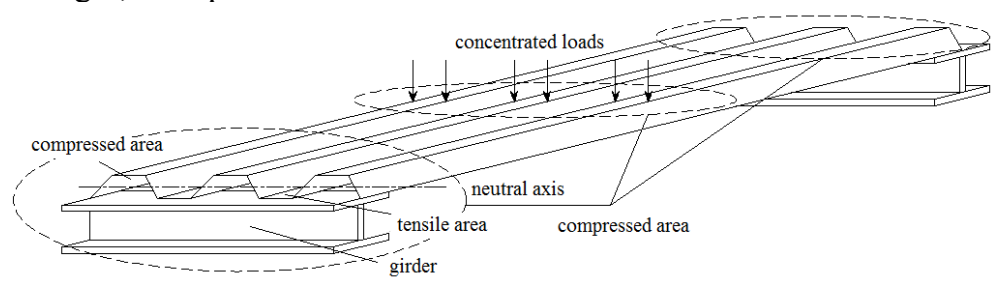

Figure 1 CSP Platform Structure 
This kind of platform is mainly applied in the architectural engineering called Composite Floor, the thickness of steel plate used in Composite Floor is less than $1.5 \mathrm{~mm}$, but the thickness of CSP is usually from $3 \mathrm{~mm}$ to $10 \mathrm{~mm}$, maybe thicker. The increasing of the thickness will supply higher bearing capacity.
In this paper, the experimental test of CSP platforms will be conducted with the following three kinds of dimensions: $400 \times 50 \times 3 \mathrm{~mm}$ (Width, Height and Thickness), $500 \times 50 \times 5 \mathrm{~mm}$ and $500 \times 86.6 \times 5 \mathrm{~mm}$. The span of the structure is $2390 \mathrm{~mm}$, the distance of the support of the distribution beam is $800 \mathrm{~mm}$, and CSP section characteristics are shown in Figure 2 and table 1.

\subsection{Experimental Test}

a)

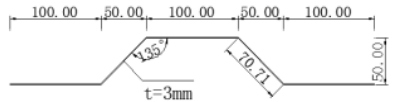

b)

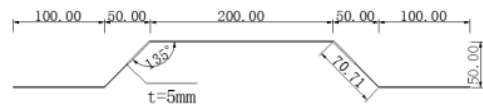

c)

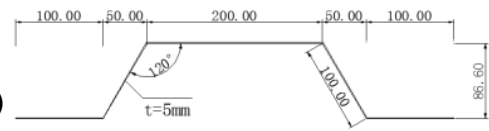

Figure 2 Graphic Presentations of CSP: a) CSP1; b) CSP2; c) CSP3

Table 1 Section Properties of CSP

\begin{tabular}{ccccc}
\hline Components & $\begin{array}{c}\text { Moment of inertia } \\
\mathrm{I} / \mathrm{mm}^{4}\end{array}$ & $\begin{array}{c}\text { Area } \\
\mathrm{A} / \mathrm{mm}^{2}\end{array}$ & $\begin{array}{c}\text { plastic modulus } \\
\mathrm{S} / \mathrm{mm}^{3}\end{array}$ & $\begin{array}{c}\text { Height of centroid } \\
\mathrm{y} / \mathrm{mm}\end{array}$ \\
\hline CSP1 & 611676 & 1324 & 26471.9 & 20 \\
CSP2 & 1043717 & 2707 & 58875.3 & 27.5 \\
CSP3 & 4382812 & 3000 & 108189.7 & 45.8 \\
\hline
\end{tabular}

Testing loads are controlled by the variation of load-displacement law, CSP1: the load step is $3 \mathrm{kN}$, and break for 1 minute at the end of each load step, until reaching the ultimate bearing capacity; CSP2, CSP3: the load step is $5 \mathrm{kN}$, and break for 1 minute at the end of each load step, until reaching the ultimate bearing capacity.

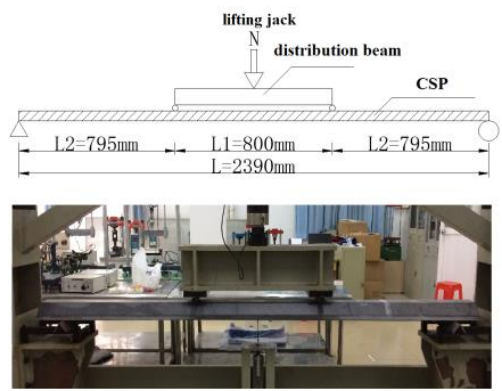

Figure 3 Loading Plan

\section{Result Analysis and Discussion}

The load-displacement curves obtained by experimental tests are drawn in Figure 4. According to the bearing capacity curve of Figure 4 , it is seen that the ultimate bearing capacity of CSP1 is $30 \mathrm{kN}, \mathrm{CSP} 2$ is $67.1 \mathrm{kN}$ and CSP3 is $125 \mathrm{kN}$. All CSPs showed good elastic performance, load-displacement curve is basically linear before yielding.

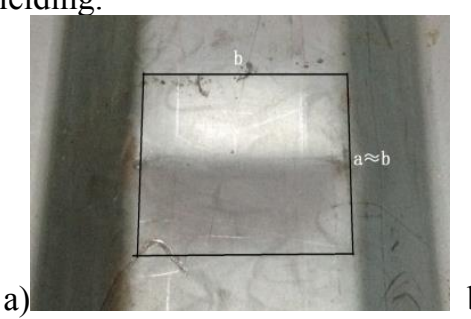

b)
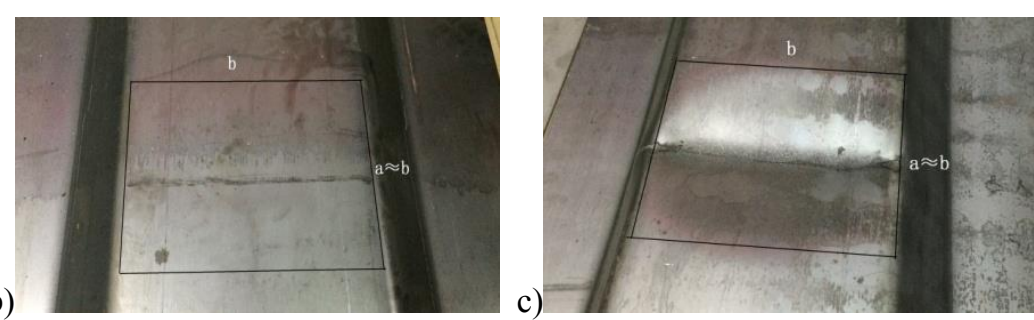

Figure 5 Deformation of Loading Position: a) CSP1; b) CSP2; c) CSP3

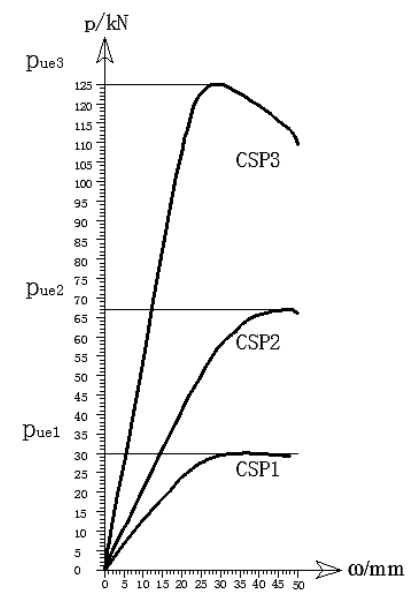

Figure 4 Load - Displacement Curves

The deformations of the loading position are shown in Figure 5, both CSP1 and CSP3 show as elastic-plastic buckling, which occurred after yielding with unrecoverable deformation; CSP2 shows as elastic buckling, the plate deformed in the process of loading and deformation recovered when the load was removed. The deformations of the loading point illustrates that the ultimate bearing capacity of the components is relevant to the local buckling. 


\section{Analysis of Local Buckling}

The mechanical behavior of local compressive position of CSP is very complicated. It contains vertical concentrated loads and bending stress in the roof and web. Furthermore, since the web skews cross the roof, the concentrated loads will be decomposed into two component forces along the direction of the web and roof. In addition, the relationship between the roof and the web buckling must be considered. Combining these factors above, local buckling is very difficult to be analyzed. The calculation diagram is shown in Figure 6.

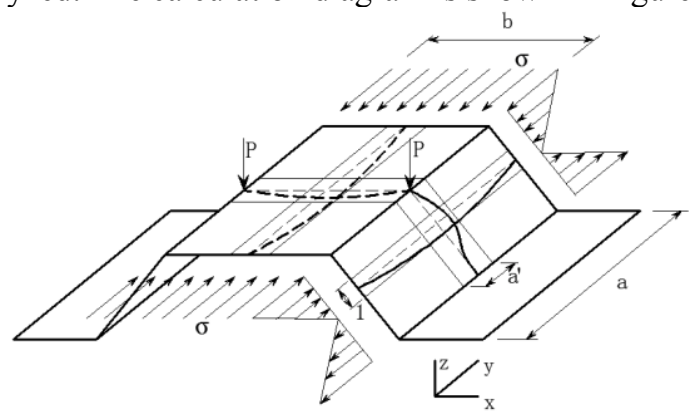

Figure 6 Analysis Diagram of Local Buckling

The bending stress $\sigma$ in Figure 6 can be solved easily according to bending theory. The parameters $a$ and $b$ both are half wavelength, which should be calculated by the differential equation of plate buckling [17].

\subsection{Half Wavelength}

Due to the skew between the web and the roof, the horizontal component force of the $\mathrm{X}$ direction will be generated in the roof under the vertical load P, and the roof will be in a state of biaxial compression. In which, $p_{y}$ is produced by the bending stress of the roof, and $p_{x}$ is produced by the horizontal component force of $\mathrm{P}$.

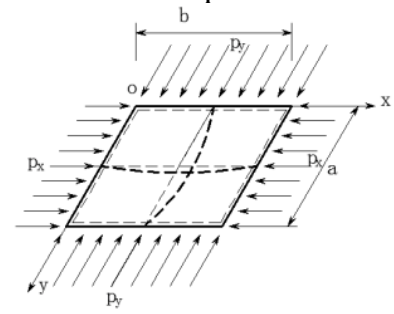

Figure 7 Simply Supported Plate of Two-way Compression

The solutions of buckling modes of biaxial compression can be used to solve the half wavelength a and $b$.
The equilibrium equation is:

$D\left(\frac{\partial^{4} \omega}{\partial x^{4}}+2 \frac{\partial^{4} \omega}{\partial x^{2} \partial y^{2}}+\frac{\partial^{4} \omega}{\partial y^{4}}\right)+p_{x} \frac{\partial^{2} \omega}{\partial x^{2}}+p_{\mathrm{y}} \frac{\partial^{2} \omega}{\partial \mathrm{y}^{2}}=0$

Assuming the deflection surface equation is a trigonometric series, the following equation is obtained.

$\omega=\sum_{m=1}^{\infty} \sum_{n=1}^{\infty} A_{\mathrm{mn}} \sin \frac{m \pi x}{a} \sin \frac{n \pi y}{b}$

Where: $m, n$ - the half wave number of $X$ and $Y$ direction; $\mathrm{A}_{\mathrm{mn}}$ - undetermined constant.

The relationship between buckling load $p_{x}$ and $p_{y}$ can be obtained by assuming the half wave numbers of two directions are 1 , and meet with the condition of both $A_{m n}$ and the sine term value is not zero.

$\frac{p_{x}}{a^{2}}+\frac{p_{y}}{b^{2}}=\pi^{2} D\left(\frac{1}{\mathrm{a}^{2}}+\frac{1}{b^{2}}\right)^{2}$

Make $\lambda=a / b$, the formula above becomes as:

$p_{x}+\lambda^{2} p_{y}=\frac{\pi^{2} D}{b^{2}}\left(\frac{1}{\lambda}+\lambda\right)^{2}$

When $\lambda=1$ (that is $\mathrm{a}=\mathrm{b}$ ), the formula above will achieve the minimum, and buckling will occur easily, in this time:

$p_{\text {crx }}+p_{c r y}=\frac{4 \pi^{2} D}{b^{2}}$

Therefore, when the simple supported plate is compressed by two directions, buckling modes will generate with the same value of half wave numbers in two directions, that is $\mathrm{a}=\mathrm{b}$. In this view, this problem can be solved only when $a$ or $b$ is known. Here, the value of $b$ is just equal to the width of roof, so buckling will produce a square grid region with length $b$, this agrees with the square caused by local buckling in figure 5 .

\subsection{Analysis of Local Buckling}

It is complicated to analyze the buckling mode shown in Figure 6, and the buckling differential equation cannot be used to solve this problem directly. Therefore, the buckling mode of CSP is decomposed along the $\mathrm{X}$ direction and the $\mathrm{Y}$ direction, in this way, the three-dimensional buckling problem is transformed into two-dimension plane buckling problem. In X direction, the buckling problem is considered as the buckling of plane rigid frame, and the influence of $\mathrm{Y}$ direction is considered as the constraint of $\mathrm{X}$ direction. Considering the composite buckling of the roof and web, this problem can be solved successfully.

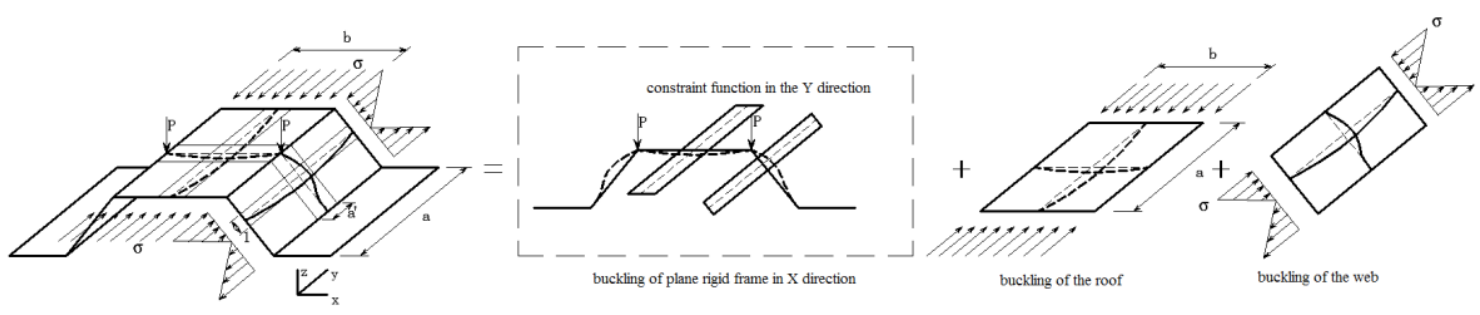

Figure 8 Analysis Diagram of Local Buckling

1) Buckling of plane rigid frame in $X$ direction

The stability analysis is carried out by using buckling theory of rigid frame [18]. 


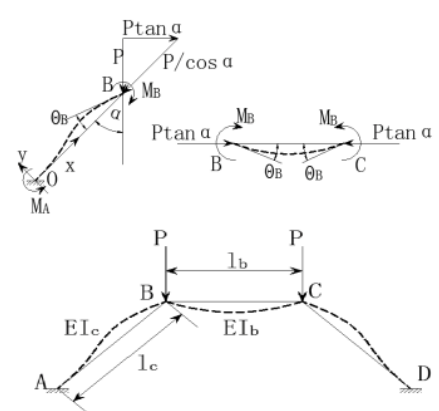

Figure 9 Buckling of Plane Rigid Frame

The load $\mathrm{P}$ is decomposed along the direction of the inclined web and the roof, the component force along the web $\mathrm{P} / \cos \alpha$ and along the roof Ptan $\alpha$ can be obtained. Buckling of the inclined web and roof will take place under the action of axial compressive loads, and the buckling equation is established according to the equal rotation of the point B, see Figure 9.

The differential equation of inclined web is:

$\mathrm{y}_{c}^{\prime \prime}+k_{c}^{2} y_{c}=\frac{M_{B}-M_{A}}{E I_{c} l_{c}} x_{c}+\frac{M_{A}}{E I_{c}} \quad k_{\mathrm{c}}^{2}=\frac{P}{E I_{c} \cos \alpha}$

The following formula will be obtained by solving differential equations above.

$y_{c}=-\frac{M_{B}-M_{A}}{P k_{c} l_{c}} \cos \alpha \sin k_{c} x_{c}-\frac{M_{A}}{P} \cos \alpha \cos k_{c} x_{c}+\frac{M_{B}-M_{A}}{P l_{c}} x_{c} \cos \alpha+\frac{M_{A} \cos \alpha}{P}$

$M_{A}=\frac{\sin k_{\mathrm{c}} x_{c}-k_{c} l_{c}}{\sin k_{\mathrm{c}} x_{c}-k_{c} l_{c} \cos k_{c} l_{c}} M_{B}$

$\theta_{B}=\frac{2 k_{c} l_{c}-2 k_{c} l_{c} \cos k_{c} l_{c}-\left(k_{c} l_{c}\right)^{2} \sin k_{c} l_{c}}{\sin k_{c} l_{c}-k_{c} l_{c} \cos k_{c} l_{c}} \times \frac{M_{B} \cos \alpha}{P l_{c}}$

The differential equation of the roof is:

$\mathrm{y}_{\mathrm{b}}^{\prime \prime}+k_{b}^{2} y_{b}=\frac{M_{B}}{E I_{b}} \quad k_{b}^{2}=\frac{P \tan \alpha}{E I_{b}}$

The following formula will be obtained by solving differential equations above.

$y_{b}=\frac{M_{B}+M_{B} \cos k_{b} l_{b}}{P \tan \alpha \sin k_{b} l_{b}} \sin k_{b} x_{b}-\frac{M_{B}}{P \tan \alpha} \cos k_{b} x_{b}+\frac{M_{B}}{P \tan \alpha}$

$y_{\mathrm{b}}^{\prime}=\frac{M_{B}+M_{B} \cos k_{b} l_{b}}{P \tan \alpha \sin k_{b} l_{b}} k_{b} \cos k_{b} x_{b}+\frac{M_{B}}{P \tan \alpha} k_{b} \sin k_{b} x_{b}$

$y_{\mathrm{b}}^{\prime}(0)=\frac{M_{B}+M_{B} \cos k_{b} l_{b}}{P \tan \alpha \sin k_{b} l_{b}} k_{b}$

The correlation equation between the roof and the inclined web is established according to the equal rotation of point B.

$\frac{M_{B}+M_{B} \cos k_{b} l_{b}}{P \tan \alpha \sin k_{b} l_{b}} k_{b}=\frac{2 k_{c} l_{c}-2 k_{c} l_{c} \cos k_{c} l_{c}-\left(k_{c} l_{c}\right)^{2} \sin k_{c} l_{c}}{\sin k_{c} l_{c}-k_{c} l_{c} \cos k_{c} l_{c}} \times \frac{M_{B} \cos \alpha}{P l_{c}}$

$\frac{1+\cos k_{b} l_{b}}{\tan \alpha \sin k_{b} l_{b}} k_{b}=\frac{2 k_{c} l_{c}-2 k_{c} l_{c} \cos k_{c} l_{c}-\left(k_{c} l_{c}\right)^{2} \sin k_{c} l_{c}}{\sin k_{c} l_{c}-k_{c} l_{c} \cos k_{c} l_{c}} \times \frac{\cos \alpha}{l_{c}}$

Simplifying the formula above, obtain:

$\tan \left(\frac{k_{b} l_{b}}{2}\right)=\frac{2-2 \cos k_{c} l_{c}-\left(k_{c} l_{c}\right) \sin k_{c} l_{c}}{\sin k_{c} l_{c}-k_{c} l_{c} \cos k_{c} l_{c}} \sqrt{\sin \alpha}$

The tangent value of the left side of the equation is $0 \sim \infty$. When the left side is 0 , the right side will become the following:

$\frac{2-2 \cos k_{c} l_{c}-\left(k_{c} l_{c}\right) \sin k_{c} l_{c}}{\sin k_{c} l_{c}-k_{c} l_{c} \cos k_{c} l_{c}}=0$

$k_{\mathrm{c}} l_{\mathrm{c}}=\pi / 0.5$ is obtained by solving the equation above.
When the left side is $\infty$, the right side will become the following:

$\frac{2-2 \cos k_{c} l_{c}-\left(k_{c} l_{c}\right) \sin k_{c} l_{c}}{\sin k_{c} l_{c}-k_{c} l_{c} \cos k_{c} l_{c}}=\infty$

$k_{\mathrm{c}} l_{\mathrm{c}}=\pi / 0.7$ is obtained by solving the equation above.

Make $\pi / \mu=k_{\mathrm{c}} l_{\mathrm{c}}, \mu$ will be change from 0.5 to 0.7 with different tangent values.

It is difficult to solve the equation above exactly, which needs to be constantly repeated to get the buckling load P.

\section{2) Influence of Y Direction}

The buckling analysis above is based on the considerations of buckling of plane frame in $\mathrm{X}$ direction, but the slab in $\mathrm{Y}$ direction will produce restraint to the buckling in $\mathrm{X}$ direction, which will increase the buckling loads. The constraint function in the $\mathrm{Y}$ direction can be solved by bending differential equation of plate with 4 sides simply supported [19].

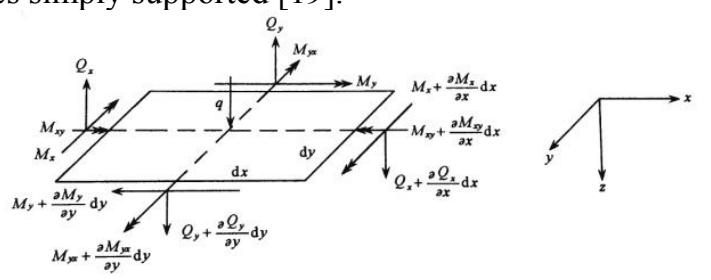

Figure 10 Infinitesimal Body of Plate is:

The differential equation corresponding to figure 10

$D\left(\frac{\partial^{4} \omega}{\partial x^{4}}+2 \frac{\partial^{4} \omega}{\partial x^{2} \partial y^{2}}+\frac{\partial^{4} \omega}{\partial y^{4}}\right)=q$

The solution of $\omega$ is the key to calculating the internal force of the plate. With the solution of $\omega$ obtained above, the constraint problem in Y direction has been solved too. Fortunately, $\omega$ has been solved.

When there is no constraint in $\mathrm{Y}$ direction, the internal force of the plate is transmitted along the $\mathrm{X}$ direction, in this way, the $3 \mathrm{D}$ space problem can be reduced to a $2 \mathrm{D}$ problem. When the constraint of $\mathrm{Y}$ direction is considered, the internal force problem becomes a 4-side simply supported slab problem. The structural stress state of the two cases mentioned above can be converted by the deflection ratio.

Supposing that $\mathrm{P}_{1}$ is the buckling load without considering the constraint of $\mathrm{Y}$ direction, while $\mathrm{P}_{2}$ is the buckling load with the constraint of $\mathrm{Y}$ direction, $\omega_{1}$ is the deflection of the plate simply supported by both sides caused with unit force, $\omega_{2}$ is the deflection of the plate simply supported by 4 sides caused with unit force, then the relationship between $P_{1}$ and $P_{2}$ can be expressed as: $\frac{P_{1}}{P_{2}}=\frac{\omega_{2}}{\omega_{1}}$

The ratio of the deflection $\omega$ of the center point is associated with the ratio of the lengths of the two directions of simple supported plate, which is given by Table 2 [20].

Table 2 Load Conversion Coefficient of Buckling Considering Constrains in y Direction

\begin{tabular}{llllllllllll}
\hline$l_{1} / l_{2}$ & 0.5 & 0.55 & 0.6 & 0.65 & 0.7 & 0.75 & 0.8 & 0.85 & 0.9 & 0.95 & 1.0 \\
\hline
\end{tabular}




\begin{tabular}{llllllllllll}
\hline$\omega_{2} / \omega_{1}$ & 0.778 & 0.722 & 0.666 & 0.611 & 0.558 & 0.509 & 0.463 & 0.42 & 0.381 & 0.345 & 0.312 \\
\hline
\end{tabular}

Where: $l_{1}$ - length of short edge; $l_{2}$ - length of long edge; when $l_{1} / l_{2}$ is less than 0.5 , the situation can be considered as without constraints in Y direction.

\section{3) Width of Plane Rigid Frame in X Direction.}

When the buckling problem of plane rigid frame and the constraint of Y direction is solved, the stiffness of the frame $\mathrm{I}_{b}$ and $\mathrm{I}_{\mathrm{c}}$, which are relevant to the width of plane rigid frame, needs to be solved, the key parameter to solve $I_{b}$ and $I_{c}$ is a', shown in Figure 6 and Figure 8 .

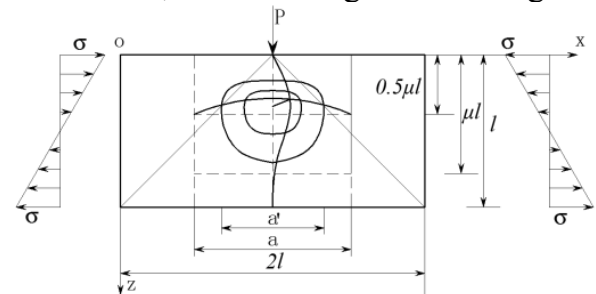

Figure 11 Determination Method of a'

According to "Code for Design of Steel Structures", when the load is applied to the top of the web, it will diffuse along the web with 45 degree angle, and the stress is gradually decreasing along the structural height direction.
If the height of web is $l$, the distribution width of the bottom will be $2 l$. Assuming the width with $l$ or $2 l$ in the plane rigid frame is not suitable obviously, because the stress distribution is not uniform. So, a relatively concentrated area need to be found, and assuming the stress distribution is uniform in this area, load $\mathrm{P}$ is mainly borne by the width of the strip in this area.

In the theory of elastic stability, $\mu l$ is used to calculate the length of the compression column according to the different supporting conditions. The largest deformation and the maximum internal force is in $0.5 \mu \mathrm{l}$ position of the component. So, the stress distribution width of the web in $0.5 \mu l$ position (Figure 11) is $\mathrm{a}^{\prime}=\mu l$ (when $\mu l<\mathrm{a}$; if $\mu l>\mathrm{a}$, $\mathrm{a}=\mathrm{a})$. With the assumption that the load $\mathrm{P}$ is uniformly distributing along the width, see Figure 11.

\section{4) Buckling relevant equation}

When buckling load of the plane rigid frame is calculated, buckling of the roof and web (Figure 8) needs to be considered, which affect the buckling of local area. Buckling of the roof and web can be solved by the methods mentioned in reference [21].

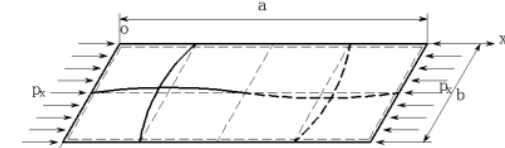

a) $y$

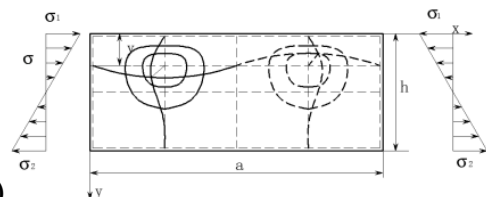

$\sqrt{y}$

Figure 12 Simplified Model of Buckling; a) Buckling of the roof; b) Buckling of the web

Table 3 Calculation Formula of Local Buckling

\begin{tabular}{cccc}
\hline Category & Critical stress & $\mathrm{k}$ & $\chi$ \\
\hline $\begin{array}{c}\text { Buckling of the } \\
\text { roof }\end{array}$ & $\sigma_{\mathrm{crx}}=\frac{\chi k}{12\left(1-v^{2}\right)} \times \frac{\pi^{2} E}{(\mathrm{~b} / \mathrm{t})^{2}}$ & 4 & 1.3 \\
$\begin{array}{c}\text { Buckling of the } \\
\text { web }\end{array}$ & $\sigma_{\mathrm{cr} x 1}=\frac{\chi k}{12\left(1-v^{2}\right)} \times \frac{\pi^{2} E}{(\mathrm{~h} / \mathrm{t})^{2}}$ & 23.9 & 1.0 \\
\end{tabular}

When the three parts decomposed in Figure 8 are solved. The buckling relevant equation is used to estimate whether buckling happens in local area. If $\mathrm{P}>\mathrm{P}_{\mathrm{y}}$, it is elastic-plastic buckling, otherwise, it's elastic buckling.

The buckling relevant equation can be expressed as:

$$
\frac{P}{P_{c r}}+\frac{\sigma_{x}}{\sigma_{c r x}}+\frac{\sigma_{x 1}}{\sigma_{c r x 1}}=1
$$

The following equation will be obtained after all expression introducing into equation (2).

$$
\frac{P}{\frac{\pi^{2} E I_{c}}{\left(\mu l_{c}\right)^{2}}}+\frac{\frac{M}{I} y_{c}}{\frac{\chi_{1} k_{1} \pi^{2} E}{12\left(1-v^{2}\right)(b / t)^{2}}}+\frac{\frac{M}{I} y_{c}}{\frac{\chi_{2} k_{2} \pi^{2} E}{12\left(1-v^{2}\right)(h / t)^{2}}}=1
$$

Notice: the relationship between $P$ in equation (3) and $P$ in load-displacement curve in Figure 4 is that the value of $P$ in equation (3) is equal to $1 / 4$ of the value of $P$ in Figure 4, which is the distribution load of the lifting jack. So to make these two unified, the equation (3) becomes the following form:

$$
\frac{\frac{P}{4}}{\frac{\pi^{2} E I_{c}}{(\mu h)^{2}}}+\frac{\frac{P L_{2}}{2 I} y_{c}}{\frac{\chi_{1} k_{1} \pi^{2} E}{12\left(1-v^{2}\right)(b / t)^{2}}}+\frac{\frac{P L_{2}}{2 I} y_{c}}{\frac{\chi_{2} k_{2} \pi^{2} E}{12\left(1-v^{2}\right)(h / t)^{2}}}=1
$$

Where: $l_{\mathrm{c}}$ - the height of the wed, $l_{\mathrm{c}}=\mathrm{h}$.

The equation (4) is the formula to calculate the local buckling under the loads shown in Figure 3. $\mathrm{P}_{\mathrm{cr}}=\pi^{2} \mathrm{EI}_{\mathrm{c}} /(\mu \mathrm{h})^{2}, \mathrm{P}_{\mathrm{cr}}$ can be obtained if the value of $\mu \mathrm{h} / \mathrm{b}$ agree with table 2 or not.

Where: $\mathrm{I}_{\mathrm{c}}-$ moment of inertia of the web with width a', a' $t^{3} / 12$; P- concentrated load applied by lifting jack; E-elastic modulus of steel; $\mu$ - calculating factor of length; h- height of CSP; $v$ - Poisson's ratio; $\chi_{1}, \chi_{2}$ - the elastic restraint coefficient; $b$ - width of the roof; $t$ - thickness of the plate; $\mathrm{k}_{1}, \mathrm{k}_{2}$ - local buckling coefficient; I- moment of inertia of CSP; $\mathrm{y}_{\mathrm{c}^{-}}$distance from centroid to the roof; $\mathrm{L}_{2}-$ distance from loading point to support point.

\subsection{Method validation and discussion}

The calculation results of CSP1, CSP2 and CSP3 are summarized in Table 4.

Table 4 Results of Buckling Calculation

\begin{tabular}{ccccc}
\hline component & $\mu=0.5$ & $\mu=0.7$ & $\mathrm{P}_{\text {ue }}$ & conclusions \\
\hline $\mathrm{CSP} 1$ & $37.6 \mathrm{kN}$ & $36.6 \mathrm{kN}$ & $30 \mathrm{kN}$ & yielding
\end{tabular}




\begin{tabular}{lcccc} 
CSP2 & $67.8 \mathrm{kN}$ & $67.08 \mathrm{kN}$ & $67.1 \mathrm{kN}$ & buckling \\
CSP3 & $144.7 \mathrm{kN}$ & $140 \mathrm{kN}$ & $125 \mathrm{kN}$ & yielding \\
\hline
\end{tabular}

$P_{\text {cr }}$ calculated by formula (4) can only give the distribution range, when the stiffness of the roof from 0 to $\infty$, which correspond to the situation of $\mu=0.5$ and $\mu=0.7$, it is very difficult to give an exact result. According to table 4 , the buckling load range of CSP1 is $36.6 \mathrm{kN}-37.6 \mathrm{kN}$, which is greater than the experimental load, the ultimate bearing capacity is controlled by the bending strength; The buckling load range of CSP2 is $67.08 \mathrm{kN}-67.8 \mathrm{kN}$, the experimental load is between the range, the ultimate bearing capacity is controlled by the buckling strength of the structure; The buckling load range of CSP3 is $140 \mathrm{kN}-144.7 \mathrm{kN}$, which is greater than the experimental load, the ultimate strength is controlled by the bending strength. The results above agree with the experimental results, which illustrate the formula (4) is reasonable. For checking general buckling under concentrated loads, formula (3) is required to be changed to establish the relevant equations of the rigid frame, the roof and the web.

Thickness ratio of the roof of CSP1 is $100 / 3=33.3$, and the web is $70.71 / 3=23.57$, which are close to or less than $b / t=30$. Thickness ratio of the roof of CSP2 is $200 / 5=40$, and the web is $70.71 / 5=14.142$, which are greater or less than $b / t=30$; thickness ratio of the roof of CSP3 is $200 / 5=40$, and the web is $100 / 5=20$, which are greater or less than $b / t=30$. It is not accurate to judge if buckling of CSP takes place or not according to thickness ratio of the plate. The "code for design of steel structures" [21] stipulates that: when the width-thickness ratio $b / t$ is less than or equal to 30 , local buckling won't take place, experimental phenomena does not conform to the provisions in the code obviously, so the width-thickness ratio can't be used to determine whether buckling of CSP take place or not.

According to the analysis above, the buckling load calculated by formula (4) is reliable. Since the buckling calculation is only relevant to the stiffness of the components and not relevant to the strength of materials, which does not need to be obtained by the material stress-strain relationship. The buckling capacity calculated by the stiffness agrees with the experimental phenomena and results very well, so the formula is reasonable.

The boundary condition of the plane rigid frame is simplified to fixedly connect with the foundations, but the actual boundary condition of the structure is elastic boundary. The bottom plate is partly tensile and partly compressive, the tensile stress will increase the buckling capacity in compressive direction. The concentrated force acts on the roof, which will be transferred to the bottom plate, the transferred pressure is less than that of the roof. The buckling of the web will only take place near the roof. When these factors were considered, the fixed connected boundary condition of plane rigid frame is reasonable.

Experiment used one waveform of CSP, which is not fully reflect the actual structure, but due to the bottom plate of CSP is pulled and is not prone to buckling, so the whole section of actual structure can be divided into a number of single waveform by bottom plates. Buckling loads of actual structure and one waveform of CSP are similar in this paper, so the analysis method and the experimental method are reasonable.

\section{Conclusion}

The following conclusions can be drawn by the analysis above:

Load-displacement curve of CSP is basic linear before yielding which shows these structures have good elastic properties; the final failure mode has two kinds: one is yielding with the plastic deformation; the other is the elastic buckling with the instable elastic deformation.

Checking if local buckling takes place at the loading point or not, formula (4) can be used. In general cases, formula (3) can be used. The formula includes three parts: buckling of the simplified plane rigid frame, buckling of the roof and the web. Buckling loads calculated by the formula agree with the experimental results very well, which can be used to determine the local buckling loads.

\section{References}

1. Minkwan Ju, Hongseob Oh. Static and fatigue performance of the bolt-connected structural jointed of deep corrugated steel plate member[J]. Advances in Structural Engineering, 2016, 19 (9): 1435-1445.

2. Damian BEBEN, Adam STRYCZEK. NUMERICAL ANALYSIS OF CORRUGATED STEEL PLATE BRIDGE WITH REINFORCED CONCRETE RELIEVING SLAB[J]. JOURNAL OF CIVIL ENGINEERING AND MANAGEMENT, 2016, 22 (5): 585-596.

3. LI Bai-jian, FU Xin-sha, JIANG Xiao-li. Technology of Corrugated steel plate - concrete composite beam used in bridge reinforcement [J]. Highway, 2016, 10: 77-80.

4. CHEN Shui-sheng, ZHANG Xiaop-guang, GUI Shui-rong. Parametric Analysis of Dynamic Characteristics of Multi-Cell Single-Box Composite Box Girder Bridge with Corrugated Steel Webs[J]. Bridge Construction, 2014, 44 (6): 40-45.

5. LI Jie, WU Hai-peng, CHEN Huai. Analysis of Steel Web Shear Capacity of Variable Section Continuous System Composite Box Beam Bridge with Corrugated Steel Webs[J]. Bridge Construction, 2015, 45 (1):79-84.

6. Nie Jianguo, Zhu Li, Tang Liang. Shear strength of trapezoidal corrugated steel webs[J]. CHINA CIVIL ENGINEERING JOURNAL, 2013, 46 (6): 97-109

7. Tong Guo, Richard Sause. Analysis of local elastic shear buckling of trapezoidal corrugated steel webs[J]. Journal of Constructional Steel Research, 2014, 102: 59-71.

8. LI Ming-hong, YANG Bing-wen, WANG Yi-li etc. Design Method of Corrugated Steel Webs in Prestressed Concrete Composite Girder with the 
Webs [J]. Journal of Highway and Transportation Research and Development, 2013, 30 (6): 40-44.

9. Zhang Feng, Li Shucai, Ye Jianshu etc. Shear strength of corrugated steel web partially encased with concrete[J]. JOURNAL OF SOUTHEAST UNIVERSITY (Natural Science Edition), 2016, 46 (6): 1264-1270.

10. Yang Le, Zheng Kaifeng. Research on the dynamic properties of steel bottom slab and corrugated steel web bridge[J]. Gummi, Fasern, Kunststoffe, 2016, 69 (13): 218-224.

11. Moon Jiho, Ko Hee-Jung, Sung Ik Hyun etc. Natural frequency of a composite girder with corrugated steel web [J].Steel and Composite Structures, 2015, 18 (1): 255-271.

12. ZHAO Jun-hao. Corrugated steel-reinforced concrete combination bridge panel capacity experiment [D]. Nanchang: East China Jiaotong University, 2012.

13. XU Jia-qi. Corrugated steel-reinforced concrete combination bridge panel capacity experiment [D]. Nanchang: East China Jiaotong University, 2012.

14. SU Qing-tian, TIAN Le, ZENG Ming-gen etc. RESEARCH ON BASIC PERFORMANCE OF COMPOSITE BRIDGE DECKS WITH ORTHOTROPIC CORRUGATED STEEL PLATES AND CONCRETE [J]. ENGINEERING MECHANICS, 2016, 33(suppl): 138-142.

15. HU Su, SU Qing-tian, WU Chong. Study on the Section Optimization of the Orthotropic Steel-composite Bridge Deck [J]. Structural Engineers. 2015, 31 (2): 131-137.

16. WANG Xin-min. ANSYS Numerical Analysis of Engineering structures $[\mathrm{M}]$. Beijing: China Communication Press, 2007.

17. Timoshenko S P, Gere J M. Theory of Elastic Stability, 2nd, Ed. McGraw-Hill, 1961, 180.

18. Chen W F, Liu E M. Structural Stability-Theory and Implementation, Elsevier, New York, 1987.

19. Han Qiang. Higher plate and shell theory [M]. Science Press Ltd. 2002. 01

20. Shu Shi-lin. Design of Reinforced Concrete Structures (Third edition) [M]. Zhejiang University Press. 2011.

21. GB. 50017-2014, Code for design of steel structure[S]. Beijing: China Architecture \& Building Press, 2014. 